\title{
PENGEMBANGAN MODUL PERAWATAN DAN PERBAIKAN SASIS PEMINDAH TENAGA KELAS XI SMKN 2 KLATEN
}

\author{
Anna Insya*1, Sukaswanto ${ }^{1}$ \\ Jurusan Pendidikan Teknik Otomotif, Universitas Negeri Yogyakarta \\ *Corresponding author: anna.insya2016@student.uny.ac.id
}

\begin{abstract}
Abstrak
Penelitian ini bertujuan untuk mengetahui prosedur pengembangan dan kelayakan modul mata pelajaran Perawatan dan Perbaikan Sasis, Pemindah Tenaga Otomotif untuk kelas XI di SMK N 2 Klaten. Penelitian ini adalah jenis penelitian R\&D dengan model pengembangan 4D oleh Thiagarajan, tahapannya yaitu: Define, Design, Develop, dan Disseminate. Data diperoleh dari penilaian seorang ahli media dan seorang ahli materi serta respon pengguna sebanyak 36 peserta didik kelas XI TMPO B di SMK N 2 Klaten. Teknik analisis data menggunakan analisis deskriptif kuantitatif. Hasil penilaian kelayakan modul pembelajaran yaitu: dari ahli media mendapat skor 3,10 dari skala 4 dengan kategori layak; dari ahli materi mendapat skor 3,29 dari skala 4 dengan kategori sangat layak; dan respon pengguna mendapat skor 3,25 dari skala 4 dengan kategori sangat layak. Dari data tersebut dapat disimpulkan bahwa Modul Perawatan dan Perbaikan Sasis, Pemindah Tenaga Otomotif (PPSPTO) kelas XI dinyatakan layak dan dapat digunakan untuk pembelajaran.
\end{abstract}

\section{Kata Kunci: modul, pemindah tenaga, $R \& D$}

\section{Abstract}

This research aims to identify the procedures and the feasibility of the Automotive Chassis \& Power Train Maintenance and Repair learning module for grade XI at SMK N 2 Klaten. This research is a research and development $(R \& D)$ with $4 D$ models by Thiagarajan. There were four stages including: Define, Design, Develop, and Disseminate. The data were obtained from the assessment of one person of media expert and one person of material expert, and user responses of 36 student of grade XI TMPO B at SMK N 2 Klaten. Data analysis techniques was using quantitative descriptive analysis. The results of the feasibility of the learning module were: from media expert got a score 3,10 on scale of 4 with feasible category, from material expert got a score 3,29 on scale of 4 with very feasible category, and from user responses got a score 3,25 on scale of 4 with very feasible category. From these data, the conclusion was the Automotive Chassis \& Power Train Maintenance and Repair (ACPTMR) learning module was declared feasible and could be used for learning.

Keywords: module, power train, $R \& D$

\section{PENDAHULUAN}

Pendidikan adalah hal penting dalam kelangsungan hidup suatu bangsa karena dengan adanya pendidikan karakter generasi penerus bangsa dapat dibentuk lebih awal agar dapat meminimalisir penyimpangan karakter sejak dini. Pendidikan sebagai dasar pembangunan karakter suatu bangsa, kemajuan suatu bangsa terletak pada sektor pendidikan di dalam Negara tersebut. Sekolah Menengah Kejuruan (SMK) adalah salah satu jenjang pendidikan menengah yang mempersiapkan lulusan untuk siap bekerja. Hal lain yaitu pendidikan sebagai salah satu sistem yang diperlukan dalam menghadai MEA (Masyarakat Ekonomi ASEAN) karena SMK 


\section{Anna Insya \& Sukaswanto}

bertugas untuk menyiapkan calon tenaga kerja tingkat menengah yang bekerja di industri perawatan dan perbaikan kendaraan bermotor (Haryana, Pambayun, Yuswono, \& Sukaswanto, 2018:67). Sejalan dengan yang disampaikan oleh Martono dan Wagiran, (2016) bahwa Sekolah Menengah Kejuruan adalah lembaga pendidikan formal yang menyiapkan siswanya untuk memiliki kompetensi berdasarkan kebutuhan tenaga kerja. SMK N 2 Klaten memiliki salah satu kompetensi keahlian yaitu Teknik Manajemen dan Perawatan Otomotif (TMPO), dalam kegiatan pembelajaran yang dilakukan terdiri dari pembelajaran teori dan praktik. Menurut Muhaimin dalam Riyanto (2010:131) pembelajaran adalah upaya membelajarkan siswa untuk belajar yang melibatkan siswa mempelajari sesuatu dengan cara efektif dan efisien. Proses pembelajaran di SMK, baik teori maupun praktik membutuhkan suatu media pembelajaran yang dapat dipelajari secara mandiri maupun dengan bimbingan guru. Seperti yang dikemukakan oleh Briggs dalam Maswan (2017:116) bahwa media adalah segala alat fisik yang dapat menyajikan pesan serta merangsang siswa untuk belajar, dapat berupa buku, film kaset dan sebagainya.

Berdasarkan hasil observasi pada saat Pengenalan Lapangan Persekolahan (PLP) pada bulan Juli 2019 diperoleh data bahwa media belajar mandiri untuk peserta didik khususnya pada Kompetensi Keahlian Teknik Manajemen dan Perawatan Otomotif (TMPO) untuk mata pelajaran Perawatan dan Perbaikan Sasis, Sistem Pemindah Tenaga Otomotif (PPSPTO) kelas XI. Pada saat proses pembelajaran, peserta didik berpusat pada materi yang disampaikan oleh guru dan informasi dari internet. Media pembelajaran yang lain untuk materi transmisi, final drive/garden, dan sistem kemudi berupa model/obyek nyata dimana model tersebut terdapat kendala untuk dapat dibawa ke dalam ruang teori dikarenakan ruang teori berada di lantai 2 . Daryanto (2016:10) mengemukakan bahwa pengembangan media hendaknya memanfaatkan kelebihan-kelebihan yang dimiliki media tersebut dan menghindari hambatan dalam proses pembelajaran. Oleh karena itu, dilakukan pengembangan modul pembelajaran pada mata pelajaran Perawatan dan Perbaikan Sasis, Sistem Pemindah Tenaga Otomotif (PPSPTO) kelas XI. Pemilihan modul untuk dilakukan pengembangan dikarenakan modul adalah suatu sumber belajar yang disusun singkat dan spesifik pada pokok bahasan tertentu untuk mencapai tujuan pembelajaran. Seperti yang dikemukakan Meyer (1978, p. 2) dalam Lasmiyati bahwa "a modul is relatively short self-contained independent unit of instructional designed to achieve a limited set of specific and well-defined educational objectives. It usually has a tangible format as a set or kit of co-ordinated and highly produced materials involving a variety of media. A module may or may not be designed for individual self-paced learning and may employ a variety of teaching techniques". Selain itu modul dapat digunakan untuk belajar secara mandiri sesuai dengan kecepatan belajar masing-masing siswa (Pranoto, 2019). Modul 
yang dikembangkan adalah modul satu tahun yang dapat digunakan untuk kelas kelas XI dalam proses pembelajaran yang terdiri dari dua semester.

\section{METODE}

Penelitian ini menggunakan model pengembangan 4-D models oleh Thiagarajan (1974:6-9) yang terdiri dari 4 tahap yaitu: 1) Define, 2) Design, 3) Develop, dan 4) Disseminate. Teknik pengumpulan data melalui observasi untuk mengetahui kondisi awal dan kuesioner untuk menentukan kelayakan modul yang dinilai oleh ahli media, ahli materi dan respon pengguna modul yaitu peserta didik kelas XI Teknik Manajemen dan Perawatan Otomotif (TMPO) B di SMK N 2 Klaten. Prosedur pengembangan modul pembelajaran ditunjukkan oleh Gambar 1.

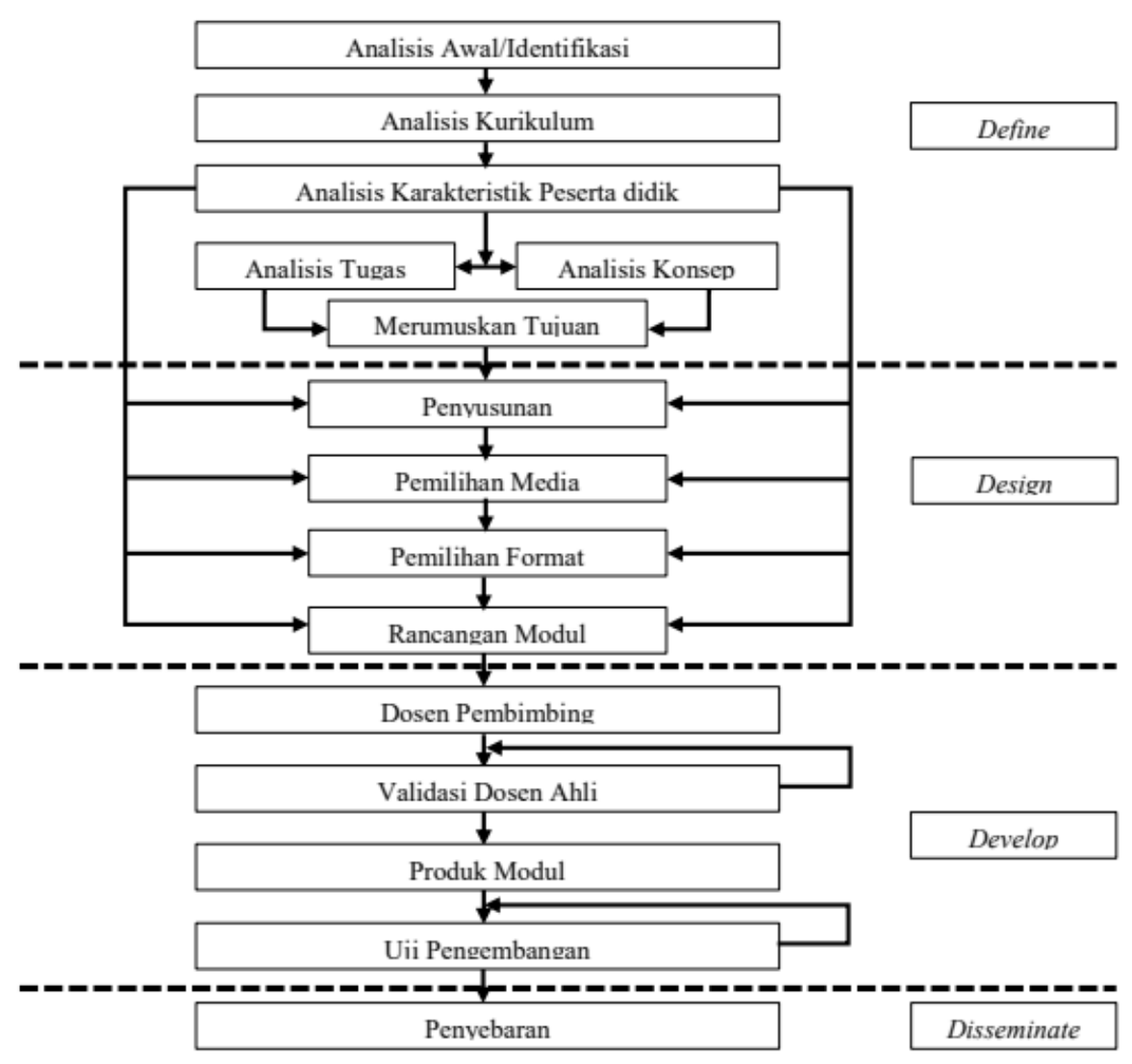

Gambar 1. Prosedur Pengembangan

Terdapat tiga instrumen dalam penelitian pengembangan ini, yaitu: 1) instrumen untuk ahli media, 2) instrumen untuk ahli materi, dan 3) instrumen untuk respon pengguna modul. Teknik analisis data yang digunakan adalah deskriptif kuantitatif dan menggunakan skala likert 1-4. Data yang diperoleh berupa gradasi skor 4, 3, 2, 1 dan kemudian dikonvesi untuk dapat dikategorikan seperti pada Tabel 1. 
Tabel 1. Kategori Penilaian

\begin{tabular}{cl}
\hline Skor Jawaban & \multicolumn{1}{c}{ Kategori } \\
\hline $\mathrm{Mi}+1,5$. Sbi $<\mathrm{X} \leq \mathrm{Mi}+3 . \mathrm{SBx}$ & Sangat Layak \\
\hline $\mathrm{Mi}<\mathrm{X} \leq \mathrm{Mi}+1,5 . \mathrm{Sbi}$ & Layak \\
\hline $\mathrm{Mi}-1,5 . \mathrm{Sbi}<\mathrm{X} \leq \mathrm{Mi}$ & Kurang Layak \\
\hline $\mathrm{Mi}-3 . \mathrm{Sbi}<\mathrm{X} \leq \mathrm{Mi}-1,5$. Sbi & Tidak Layak \\
\hline
\end{tabular}

(Sumber: Sudjana, 2017:177)

\section{HASIL DAN PEMBAHASAN}

\section{HASIL}

Penelitian ini menghasilkan produk berupa modul pembelajaran mata pelajaran Perawatan dan Perbaikan Sasis, Pemindah Tenaga Otomotif (PPSPTO) kelas XI di SMK N 2 Klaten. Modul ini dikembangkan dengan menggunakan model pengembangan 4D oleh Thiagarajan yang terdiri dari 4 tahap yaitu: Define, Design, Develop, dan Disseminate. Isi dari modul yang dikembangkan dapat dilihat pada Tabel 2.

Tabel 2. Isi Modul Perawatan dan Perbaikan Sasis, Pemindah Tenaga Otomotif (PPSPTO)

\begin{tabular}{|c|c|c|}
\hline Kegiatan Belajar & Kompetensi Dasar & Isi Materi \\
\hline Kegiatan Belajar 1 & $\begin{array}{l}3.1 \text { Menerapkan cara } \\
\text { kerja kopling }\end{array}$ & $\begin{array}{l}\text { 1. Fungsi dan kerja kopling. } \\
\text { 2. Konstruksi dan komponen-komponen } \\
\text { kopling. } \\
\text { 3. Mekanisme/cara kerja penggerak kopling. } \\
\text { 4. Cara kerja master cylinder. } \\
\text { 5. Gangguan pada unit kopling. } \\
\text { 6. Pemeriksaan unit kopling. }\end{array}$ \\
\hline Kegiatan Belajar 2 & $\begin{array}{l}3.2 \text { Menerapkan cara } \\
\text { kerja transmisi manual } \\
\text { dan otomatis }\end{array}$ & $\begin{array}{l}\text { 1. Fungsi dan kerja transmisi manual. } \\
\text { 2. Rasio roda gigi kombinasi. } \\
\text { 3. Jenis-jenis transmisi manual. } \\
\text { 4. Komponen sistem transmisi dan fungsinya. } \\
\text { 5. Cara kerja transmisi manual. } \\
\text { 6. Mekanisme pengontrol pemindah roda gigi } \\
\text { transmisi. } \\
\text { 7. Gangguan pada transmisi manual. } \\
\text { 8. Pemeriksaan transmisi manual. }\end{array}$ \\
\hline Kegiatan Belajar 3 & $\begin{array}{l}3.3 \text { Menerapkan cara } \\
\text { kerja poros propeler }\end{array}$ & $\begin{array}{l}\text { 1. Fungsi dan kerja propeller shaft. } \\
\text { 2. Konstruksi propeller shaft. } \\
\text { 3. Tipe-tipe propeller shaft. } \\
\text { 4. Cara kerja propeller shaft. } \\
\text { 5. Universal Joint. } \\
\text { 6. Center bearing. } \\
\text { 7. Gangguan pada propeller shaft. } \\
\text { 8. Pemeriksaan propeller shaft. }\end{array}$ \\
\hline
\end{tabular}




\begin{tabular}{|c|c|c|}
\hline Kegiatan Belajar 4 & $\begin{array}{l}\text { 3.4 Menerapkan cara } \\
\text { kerja differential }\end{array}$ & $\begin{array}{l}\text { 1. Fungsi dan kerja final drive/gardan. } \\
\text { 2. Konstruksi final drive/gardan. } \\
\text { 3. Cara kerja final differential, drive shaft, dan } \\
\text { axle shaft. } \\
\text { 4. Gangguan pada final drive/gardan. } \\
\text { 5. Pemeriksaan final drive/gardan. }\end{array}$ \\
\hline
\end{tabular}

Kegiatan Belajar 5 3.8 Menerapkan cara 1. Fungsi dan kerja sistem kemudi.

kerja sistem kemudi dan 2. Konstruksi sistem kemudi.

power steering 3. Cara kerja sistem kemudi.

4. Gangguan pada sistem kemudi.

5. Pemeriksaan sistem kemudi.

Penilaian kelayakan modul dilakukan oleh ahli media, ahli materi dan respon pengguna. Penilaian oleh ahli media meliputi 6 aspek yaitu: format, organisasi, daya tarik, bentuk dan ukuran huruf, ruang (spasi kosong) serta konsistensi. Hasil penilaian oleh ahli media, berdasarkan tabel kategori penilaian diperoleh rerata 3,00 pada aspek format, dan dikategorikan layak. Pada aspek organisasi diperoleh hasil rerata 3,27 dan dikategorikan sangat layak, selanjutnya pada aspek daya tarik diperoleh hasil rerata 3,10 dan dikategorikan layak, pada aspek bentuk dan ukuran huruf diperoleh hasil rerata 3,38 dan dikategorikan sangat layak, pada aspek ruang kosong diperoleh hasil rerata 3,00 dan dikategorikan layak, sedangkan pada aspek konsistensi diperoleh hasil rerata 2,88 dan dikategorikan layak. Keseluruhan hasil validasi ahli media terhadap modul Modul Perawatan dan Perbaikan Sasis, Pemindah Tenaga Otomotif (PPSPTO) diperoleh rerata penilaian sebesar 3,10 dan dikategorikan layak.

Penilaian oleh ahli materi meliputi 5 aspek yaitu: self-instructional, self-contained, stand alone, adaptive, dan user friendly. Penilaian oleh ahli materi, berdasarkan tabel kategori penilaian diperoleh hasil rerata 3,27 pada aspek self instruction, dan dikategorikan sangat layak. Pada aspek self contained diperoleh hasil rerata 3,33 dan dikategorikan sangat layak, selanjutnya pada aspek stand alone diperoleh hasil rerata 3,50 dan dikategorikan sangat layak, pada aspek adaptive diperoleh hasil rerata 3,33 dan dikategorikan sangat layak, sedangkan pada aspek user friendly diperoleh hasil rerata 3,00 dan dikategorikan layak. Keseluruhan hasil validasi ahli media terhadap modul Modul Perawatan dan Perbaikan Sasis, Pemindah Tenaga Otomotif (PPSPTO) diperoleh penilaian sebesar rerata 3,29 dan dikategorikan sangat layak.

Hasil uji pengembangan sebagai bentuk respon pengguna modul pembelajaran dilakukan oleh 36 peserta didik kelas XI TMPO B di SMK Negeri 2 Klaten. Dari hasil pengujian, berdasarkan tabel kategori penilaian diperoleh hasil rerata 3,24 pada aspek materi, dan dikategorikan layak. Pada aspek media diperoleh hasil rerata 3,31 dan dikategorikan sangat layak, sedangkan pada aspek pembelajaran modul diperoleh hasil rerata 3,13 dan dikategorikan 
layak. Keseluruhan hasil penilaian respon pengguna Modul Perawatan dan Perbaikan Sasis, Pemindah Tenaga Otomotif (PPSPTO) diperoleh penilaian sebesar 3,25 dan dikategorikan sangat layak.

\section{PEMBAHASAN}

Penelitian pengembangan ini menghasilkan produk akhir berupa modul pembelajaran Perawatan dan Perbaikan Sasis, Pemindah Tenaga Otomotif (PPSPTO). Pemilihan mata pelajaran Perawatan dan Perbaikan Sasis, Sistem Pemindah Tenaga Otomotif (PPSPTO) dikarenakan berdasarkan observasi yang dilakukan pada saat pelaksanaan Pengenalan Lapangan Persekolahan (PLP), media pembelajaran untuk mata pelajaran tersebut terbatas. Sumber belajar peserta didik untuk mata pelajaran Perawatan dan Perbaikan Sasis, Pemindah Tenaga Otomotif (PPSPTO) terbatas hanya berasal dari guru dan internet, sedangkan untuk objek/model seperti: transmisi, final drive/gardan dan sistem kemudi sulit dibawa ke ruang kelas teori, mengingat untuk ruang kelas teori kelas XI Teknik Manajemen dan Perawatan Otomotif berada di lantai 2. Oleh karena itu, pengembangan modul diperlukan untuk mengatasi hal tersebut dimana modul yang dikembangkan berupa modul berisi materi satu tahun pada mata pelajaran Perawatan dan Perbaikan Sasis, Pemindah Tenaga Otomotif (PPSPTO). Menurut Budijono dan Wahyu (2012:107) pembelajaran dengan modul bertujuan agar efisiensi, kompetensi, dan aktifitas pembelajaran dapat meningkat serta kemandirian siswa dalam proses belajar juga meningkat. Adapun kelebihan modul menurut Lasmiyati dan Hatta (2014) yaitu: 1) dapat memberikan umpan balik agar siswa mengetahui dimana kekurangannya dan memperbaikinya, 2) tujuan pembelajaran ditetapkan dengan jelas, sehingga siswa terarah untuk mencapai tujuan tersebut, 3) didesain menarik dan mudah dipelajari sehingga siswa termotivasi untuk belajar, 4) bersifat fleksibel, karena dapat dipelajari sesuai kecepatan masing-masing siswa, 5) dapat meningkatkan kerjasama, karena persaingan dapat diminimalisir antar siswa, dan 6) perbaikan dapat dilakukan secara mandiri oleh siswa sesuai dengan kelemahannya masing-masing. Pengembangan modul ini diharapkan dapat menjadi sumber belajar bagi peserta didik yang dapat digunakan secara mandiri maupun dengan bimbingan guru.

Modul Perawatan dan Perbaikan Sasis, Pemindah Tenaga Otomotif (PPSPTO) dikembangkan dengan menggunakan model pengembangan 4D yang dikemukakan oleh Thiagarajan (1974:6-9). Tahapan dalam model pengembangan 4D antara lain: 1) Define, 2) Design, 3) Develop, dan 4) Disseminate. Pada tahap Define, setelah dilakukan observasi perlu dilakukan pengembangan modul untuk mata pelajaran Perawatan dan Perbaikan Sasis, Pemindah Tenaga Otomotif (PPSPTO). Tahap Design, yaitu penyusunan draft modul. Tahap Develop, merupakan tahap penilaian modul oleh para ahli yang bertujuan untuk mendapat masukan untuk penyempurnaan produk. Setelah produk dinyatakan layak tahap selanjutnya yaitu 
penyebarluasan/disseminate. Rencana awal pada tahap penyebaran/disseminate produk akan disebarluaskan berupa cetakan, namun dikarenakan kondisi darurat akibat Covid-19 di Indonesia saat ini maka untuk penyebaran modul dilakukan dalam bentuk soft file $p d f$. Modul ini dikembangkan dengan bantuan Microsoft Word sebagai software utama dan Corel Draw X7 sebagai software pendukung.

Modul ini terdiri dari 5 kegiatan belajar seperti yang telah disampaikan sebelumnya dan merupakan materi yang diajarkan selama satu tahun atau dua semester. Modul ini telah disesuaikan dengan karakteristik modul yaitu: 1) self instruction, 2) self contained, 3) stand alone, 4) adaptive, dan 5) user friendly (Daryanto, 2014). Selain itu, modul yang dikembangkan harus memenuhi 6 elemen mutu modul, antara lain: 1) format, 2) organisasi, 3) daya tarik, 4) bentuk dan ukuran huruf, 5) ruang/spasi kosong, dan 6) konsistensi (Daryanto, 2013). Modul yang telah memenuhi karakteristik serta elemen mutu modul berdasarkan penilaian kelayakan oleh ahli media, ahli materi dan respon pengguna maka modul tersebut sudah dapat digunakan dalam pembelajaran. Modul tersebut dapat digunakan untuk pembelajaran baik secara mandiri oleh peserta didik maupun dengan bimbingan guru di dalam kelas.

\section{SIMPULAN}

Berdasarkan hasil penelitian dan pembahasan diperoleh kesimpulan bahwa pengembangan modul dengan model 4D (Define, Design, Development, dan Dissemination) disimpan dalam format $p d f$. Modul ini terdiri dari 5 kegiatan belajar, yaitu: a) kegiatan belajar 1 tentang perawatan dan perbaikan unit kopling, b) kegiatan belajar 2 tentang perawatan dan perbaikan unit transmisi, c) kegiatan belajar 3 tentang perawatan dan perbaikan unit propeller shaft, d) kegiatan belajar 4 tentang perawatan dan perbaikan unit final drive/gardan, dan e) kegiatan belajar 5 tentang perawatan dan perbaikan sistem kemudi. Hasil penilaian kelayakan dari ahli media terhadap modul Modul Perawatan dan Perbaikan Sasis, Pemindah Tenaga Otomotif (PPSPTO) diperoleh rerata skor kumulatif 3,10 dari skala 4 dan dikategorikan layak. Hasil penilaian kelayakan dari ahli materi terhadap modul Modul Perawatan dan Perbaikan Sasis, Pemindah Tenaga Otomotif (PPSPTO) diperoleh rerata skor kumulatif 3,29 dari skala 4 dan dikategorikan sangat layak. Respon pengguna Modul Perawatan dan Perbaikan Sasis, Pemindah Tenaga Otomotif (PPSPTO) mendapat rerata skor kumulatif 3,25 dari skala 4 dan dikategorikan sangat layak. 


\section{DAFTAR PUSTAKA}

Budijono, A. P. dan Wahyu, D. K. (2012). Penerapan modul berbasis komputer interaktif untuk meningkatkan kualitas proses dan hasil pembelajaran pada mata kuliah pneumatik dan hidraulik. JPTK: Jurnal Pendidikan Teknologi dan Kejuruan, Volume 21, Nomor 2, Oktober 2012, Halaman 106-113.

Daryanto. (2013). Menyusun modul: Bahan ajar untuk persiapan guru dalam mengajar. Yogyakarta: Gava Media.

. (2016). Media pembelajaran: Peranannya sangat penting dalam mencapai tujuan pembelajaran. Yogyakarta: Gava Media.

Daryanto \& Aris, D. (2014). Pengembangan perangkat pembelajaran (Silabus, RPP, PHB, bahan ajar). Yogyakarta: Gava Media.

Haryana, K., Nirmala, A. Y. P., Yuswono, L. C., \& Sukaswanto, (2018). Peranan program pelatihan dalam memantapkan kompetensi profesional guru SMK TKR. Jurnal Pendidikan Vokasi Otomotif, 1(1), 66-76.

Lasmiyati \& Hatta, I. (2014). Pengembangan modul pembelajaran untuk meningkatkan pemahaman konsep dan minat SMP. PYTHAGORAS: Jurnal Pendidikan Matematika Volume 9 - Nomor 2, Desember 2014, (161-174).

Martono, M., \& Wagiran. (2016). Developing a learning module of computer numerically control GSK 983 machines to enhance students' learning outcomes. Jurnal Pendidikan Teknologi dan Kejuruan, 23(2), 184-190.

Maswan \& Muslimin, K. (2017). Teknologi pendidikan: Penerapan pembelajaran yang sistematis. Yogyakarta: Pustaka Pelajar.

Pranoto, A. (2019). Pengembangan modul gambar teknik sebagai upaya untuk meningkatkan hasil belajar mahasiswa jurusan teknik mesin D3 IST AKPRIND Yogyakarta. Jurnal Pendidikan Vokasi Otomotif, 1(2), 95-103.

Riyanto, Y. (2010). Paradigma baru pembelajaran: Sebagai referensi bagi pendidik dalam implementasi pembelajaran yang efektif dan berkualitas. Jakarta: Kencana.

Sudjana, Nana. (2017). Penelitian hasil proses belajar mengajar. Bandung: Rosdikarya.

Thiagarajan, S. et al. (1974). Instructional development for training teachers of exceptional children. Dikutip pada tanggal 2 Desember 2019 jam 12.52 WIB dari https://www.pdfdrive.com/instructional-development-for-training-teachers-ofexceptional-children-a-sourcebook-d517006481.html 